\title{
Chronic Sclerosing Sialadenitis of the Submandibular Gland is Mainly Due to a T Lymphocyte Immune Reaction
}

Markus Tiemann, M.D., Afshin Teymoortash, M.D., Carsten Schrader, M.D., Jochen A. Werner, M.D., Reza Parwaresch, M.D., Gerhard Seifert, M.D., Günter Klöppel, M.D.

Departments of Hematopathology (MT, CS, RP) and Pathology (GK), University of Kiel; Department of Otolaryngology, Head and Neck Surgery, University of Marburg (AT, JAW); and Department of Pathology and Salivary Gland Registry, University of Hamburg (GS), Germany

The aim of our study was to investigate the role of immunopathological processes in the pathogenesis of chronic sclerosing sialadenitis of submandibular glands (Küttner tumor). For this purpose, biopsy specimens from submandibular glands of 22 patients with the histological diagnosis of chronic sclerosing sialadenitis were analyzed. Paraffin-embedded tissues were immunostained for T-lymphocyte subsets (CD3, CD4, CD8), cytotoxic $\mathrm{T}$ cells (granzyme $\mathrm{B})$, B cells (CD20, Ki-B3), and macrophages (KiM1P). Polymerase chain reaction and capillary electrophoresis were used to detect rearrangements of the $\mathrm{T}$-cell receptor gamma chain and the CDRIII region of the immunoglobulin heavy chain. In all cases, abundant cytotoxic $T$ cells were found, especially in close association with ducts and acini. T-cell receptor gamma chain rearrangements showed a monoclonal pattern in 6 cases $(27.3 \%)$, an oligoclonal pattern in 8 $(36.4 \%)$, and a polyclonal pattern in $8(36.4 \%)$. The B-cell reaction was less pronounced and largely restricted to lymph follicles. Molecular analysis of immunoglobulin heavy chain revealed a polyclonal rearrangement in 17 cases (77.3\%). In conclusion, there is an intimate relationship between the T-cell-dominated inflammatory infiltrate and acinar and duct cells. This, together with the frequent demonstration of monoclonal and oligoclonal populations of cytotoxic $T$ cells and their histopathological behavior, suggests that chronic sclerosing sialad-

Copyright () 2002 by The United States and Canadian Academy of Pathology, Inc.

VOL. 15, NO. 8, P. 845, 2002 Printed in the U.S.A.

Date of acceptance: April 29, 2002

Address reprint requests to: Markus Tiemann, M.D., Department of $\mathrm{He}-$ matopathology, University of Kiel, Niemannsweg 11, 24105 Kiel, Germany; e-mail: mtiemann@path.uni-kiel.de; fax: 49-431-5973426.

DOI: 10.1097/01.MP.0000022280.72359.04 enitis may be the result of an immune process triggered by intraductal agents.

KEY WORDS: Chronic sclerosing sialadenitis, Immune process, Immunopathology, Küttner tumor, T-cell receptor rearrangement.

Mod Pathol 2002;15(8):845-852

Chronic sclerosing sialadenitis of the submandibular gland was first described by Küttner in 1896 (1). Because of its clinical similarity to a salivary gland neoplasm, this disease has been referred to as Küttner tumor and is classified as a tumorlike lesion (2, 3). In the Salivary Gland Registry at the Department of Pathology of the University of Hamburg, chronic sclerosing sialadenitis was found to be the third most frequent cause (at 20\%) of chronic sialadenitis, exceeded only by chronic obstructive sialadenitis and chronic recurrent parotitis. Histologically, chronic sclerosing sialadenitis is difficult to distinguish from other forms of sialadenitis, particularly in advanced stages. Morphologically, it is characterized by an abundant periductal lymphocytic infiltrate and irregular ectasis of the ducts. In later stages of the disease, periductal and periacinar parenchymal fibrosis is prominent.

The cause of this inflammatory, usually unilateral disease of the submandibular gland is still unknown. The few studies that yet have been devoted to this problem have discussed a very diverse etiological spectrum. The effects of microliths (sialoliths), infectious agents, secretory dysfunctions, duct abnormalities, and immune processes have been considered (4-10). In the largest study on chronic sclerosing sialadenitis, by Seifert and Donath (11), it was pointed out that the findings in early and late chronic-sclerosing sialadenitis were similar to those in obstructive sialadenitis. The progression of the inflammatory process, however, could not be explained pathogenetically by purely 
obstructive mechanisms in the submandibular gland. Several pathohistological findings, such as the intense lymphocytic infiltration, the formation of lymph follicles, the destruction of salivary ducts, and the occasional occurrence of myoepithelial cell islets instead, suggested that immune reactions were responsible for the chronic inflammation (9). Based on these features and a comparison with the other types of sialadenitis, Seifert and Donath (11) hypothesized that initially a functional abnormality leads to inspissated secretion in the small ducts, leading to destruction of the epithelial structure of the involved gland. They called this type of salivary gland inflammation $o b$ structive electrolyte sialadenitis.

To gain a better insight into the immune process that seems to be involved in chronic sclerosing sialadenitis, exact knowledge of the composition, distribution, and clonality of the lymphocyte subpopulations is required. The only study dealing with this issue so far showed that the lymphocytic infiltrate consisted mostly of B lymphocytes and some T-helper cells, mainly localized in lymph follicles. It was therefore concluded that a thymusdependent B-cell response to an unknown agent plays a major role in chronic sclerosing sialadenitis (10). In this study, we applied modern molecular and immunohistochemical methods to determine the phenotype of immunocompetent cells in chronic sclerosing sialadenitis, study their distribution in the affected submandibular glands, and analyze the clonality pattern of their T-cell receptor gamma chain (TCR $\gamma$ ) and immunoglobulin heavychain (IGH) gene rearrangements. In particular, we wanted to know whether chronic-sclerosing sialadenitis shows an oligoclonal response pattern suggestive of an autoimmune-like reaction or a predominantly polyclonal inflammatory reaction.

\section{MATERIAL AND METHODS}

\section{Patients and Materials}

Formalin-fixed, paraffin-embedded tissue blocks from the submandibular glands of 22 patients (10 females and 12 males; mean age, 52.4 y; range, 27 to 84 y) were obtained from the files of the Department of Hematopathology of the University of Kiel and the Salivary Gland Registry of the University of Hamburg. All patients had been treated surgically because of a tumorlike swelling of a submandibular gland. Histologically, these glands were found to be affected by chronic sclerosing sialadenitis. There was no evidence of sialolithiasis as cause of an obstructive sialadenitis.

\section{Histological and Immunohistochemical Analysis}

Sections were stained with hematoxylin and eosin and with Giemsa and reviewed for the occurrence of germinal centers, the intensity and distribution of lymphocytic and monocytic infiltrates, and the degree of fibrosis. The extent of these features was graded according to Seifert's staging system (Table $1 ; 11$ ).

Lymphoid cells and macrophages were identified immunohistochemically by means of the alkaline phosphatase-anti-alkaline phosphatase and the streptavidin-biotin complex methods using monoclonal and polyclonal antibodies. All slides were stained with antibodies against the T-cell antigens CD3 (polyclonal, 1:75 dilution, DAKO, Hamburg, Germany), CD4 (monoclonal, 1:20 dilution, DAKO, Hamburg, Germany), and CD8 (monoclonal, 1:50 dilution, DAKO, Hamburg, Germany); the B-cell antigens CD20 (monoclonal, 1:80 dilution, DAKO, Hamburg, Germany), and Ki-B3 (monoclonal, undiluted, Department of Hematopathology, University of Kiel; 12, 13); and the macrophage marker Ki-M1P (monoclonal, 1:5000 dilution, Department of Hematopathology, University of Kiel; 14). Cytotoxic $\mathrm{T}$ cells were detected by means of granzyme B staining (1:20 dilution, Hölzel Diagnostika, Cologne, Germany). To quantify the lymphocytic infiltration, the periacinar and periductal cells that stained for CD3, CD4, CD8, and CD20 were counted in consecutive sections and expressed as number per high-power field $\left(0.25 \mathrm{~mm}^{2}\right.$ with a $10 \times$ eyepiece and $40 \times$ lens).

Tonsil samples from our routine files were used as positive controls for the immunohistochemical reaction.

\section{Genetic Analysis by Means of PCR and Capillary Electrophoresis}

For the DNA extraction, three $10-\mu \mathrm{m}$-thick slides were cut from a paraffin block, and the DNA was extracted according to the protocol of Wan et al.

TABLE 1. Staging System for Chronic Sclerosing Sialadenitis of the Submandibular Gland (11)

\begin{tabular}{cc}
\hline Stage No. & Indications \\
\hline 1 & $\begin{array}{c}\text { Focal periductal lymphocytic infiltration and slight increase in duct diameter } \\
\text { Increasing periductal lymphocyte infiltration, lymph follicle formation, focal metaplasia with proliferation of ductal epithelium, } \\
\text { inspissated ductal secretion, interstitial fibrosis, and beginning atrophy of acini } \\
\text { Intensive diffuse lymphocytic infiltration, periductal and intralobular lymph follicle formation, periductal hyalinization and sclerosis, } \\
\text { accentuated metaplasia of ductal epithelium, and parenchymal atrophy }\end{array}$ \\
& Fibrocytic destruction of lobular architecture, resulting in marked parenchymal loss and sclerosis \\
\hline
\end{tabular}


(15). The PCR for TCR $\gamma$ gene rearrangements was performed according to Trainor et al. (16) with two multiplex PCR. For the first reaction, variable region primers (V2, V3, V4, V8, and V9) and primers for the joining regions $(\mathrm{J} 1 / 2, \mathrm{JP} 1 / 2$, and JP) were used (Perkin Elmer, Weiterstadt, Germany). In the second reaction, a mixture of variable-region primers (V5, $\mathrm{V} 10, \mathrm{~V} 11$, and V12) and primers for the joining regions (J1/2, JP1/2, and JP) were used (Perkin Elmer; Table 2). After initial denaturation at $94^{\circ} \mathrm{C}$ for 2 minutes, PCR was begun using a hot-start protocol, and 37 cycles were performed $\left(94^{\circ} \mathrm{C} / 45\right.$ sec denaturation and $55^{\circ} \mathrm{C} / 30 \mathrm{sec}$ annealing).

To detect the IGH gene rearrangements, a seminested PCR was performed according to Wan et al. (15). For the first reaction, a primer for the FR3 region (FR3a, Perkin Elmer) and a primer for the J region of the IGH gene locus (LJH, Biometra, Göttingen, Germany) were used. In the second reaction, the primers FR3a (Perkin Elmer) and VLJH (Biometra) were used (Table 3). VLJH is a primer that binds to the J region. With these primers, the CDRIII region of the IGH gene can be amplified. After initial denaturation at $94^{\circ} \mathrm{C}$ for 2 minutes, PCR was started using a hot-start protocol, and 30 cycles were performed $\left(94^{\circ} \mathrm{C} / 60 \mathrm{sec}\right.$ denaturation, $55^{\circ} \mathrm{C} / 60 \mathrm{sec}$ annealing, and $72^{\circ} \mathrm{C} / 60 \mathrm{sec}$ extension). In the second step, 20 cycles were performed $\left(94^{\circ}\right.$ $\mathrm{C} / 60$ sec denaturation, $58^{\circ} \mathrm{C} / 60 \mathrm{sec}$ annealing, and $72^{\circ} \mathrm{C} / 60$ sec extension).

The analyses of the PCR products were done automatically by a genetic analysis system (ABI Pris, 310 Genetic Analyzer, PE Biosystems). It works with capillary electrophoresis and a laser-induced fluorescent detector. To each sample of the PCR amplificates (0.5 \&mu;L), 23.5 \&mu;L formamide (Sigma, Deisenhofen, Germany), and $1 \& \mathrm{mu}$; L of the Genescan-500 ROX-labeled internal standard (Perkin Elmer) were added before denaturation at $94^{\circ} \mathrm{C}$ for 2 minutes. The primers for the TCR $\gamma$ genes $\mathrm{J} 1 / 2$, JP1/2, and JP were labeled with fluorescent colors: HEX (yellow), TAMRA (red), and FAM (blue). The FR3a primer for the IGH genes was labeled with
TABLE 3. Sequences of the CDRIII Region Primers of the Immunoglobin Heavy Chain Gene

\begin{tabular}{ll}
\hline Primer & \multicolumn{1}{c}{ Sequence } \\
\hline FR3a & 5' ACACG GC (C/T) (G/C) T GTATT ACTGT 3' \\
LJH & 5' TGAGG AGACG GT GACC 3' \\
VLJH & 5' GTGAC CAGGG T (A/G/C/T) CCT TGGCC CCAG 3' \\
\hline
\end{tabular}

FAM (blue; Perkin Elmer). When a DNA fragment migrates into a laser-scanning area, a photomultiplier tube detects fluorescent light and converts it into an electrical signal. These signals are transmitted to a computer and analyzed with the Gene-Scan software (Gene-Scan, Version 2.02, PE Biosystems). The internal length standard is used to create a calibration curve within each lane. The length of each PCR product is determined by comparison with the calibration curve specific to each lane. The results were displayed as a chromatogram that shows the length of the fragments in base size. The clonality pattern was defined as a single predominant peak for a monoclonal population, 2 to 10 peaks for an oligoclonal population, and a sawbladelike pattern for a polyclonal population.

Every PCR of each case was done twice to support the reproducibility of the PCR pattern.

All experiments included negative and positive controls in all steps with specific test samples as follows: the T-cell line HUT 78 (American Type Culture Collection, TIB 161) was used as positive control for TCR $\gamma$, and the B-cell line BJAB (Deutsche Sammlung von Mikroorganismen und Zellkulturen GmbH, No. DSM ACG 72, Braunschweig, Germany), as positive control for IGH. DNA extract taken from paraffin-embedded tonsils served as polyclonal control tissue, and purified water, as negative control.

\section{RESULTS}

Histological and Immunohistochemical Findings

The sialadenitis observed in the 22 available specimens was characterized histologically by peri-

TABLE 2. Sequences of the Variable (V) and Joining (J) Region Primers of the TCR $\gamma$ Gene

\begin{tabular}{|c|c|}
\hline Region & Sequence \\
\hline V2 & 5' CTTC CTGCAG ATG ACT CCT ACA ACT CCA AGG TTG 3' \\
\hline V3 & 5' CTTC CTGCAG ATG ACG TCT CCA CCG CAA GGG ATG 3' \\
\hline V4 & 5' CTTC CTGCAG ATG ACT CCT ACA CCT CCA GCG TTG 3' \\
\hline V5 & 5' TTC CTGCAG ATG ACG TCT CCA ACT CAA AGG ATG 3' \\
\hline V8 & 5' CTTC CTGCAG ATG ACT CCT ACA ACT CCA GGG TTG 3' \\
\hline V9 & 5' GG(A/G/C/T)A CTGCAG GAA AGG AAT CTG GCA TTC CG 3' \\
\hline V10 & 5' CT CTGCAG AAT CCG CAG CTC GAC GCA GCA 3' \\
\hline V11 & 5’ CA CTGCAG GCT CAA GAT TGC TCA GGT GGG 3' \\
\hline V12 & 5' ACT CTGCAG CCT CTT GGG CAC TGC TCT AAA 3' \\
\hline $\mathrm{J} 1 / 2$ & 5' AAG TGT TGT TCC ACT GCC AAA 3' \\
\hline $\mathrm{JP} 1 / 2$ & $5^{\prime}$ AGT TAC TAT GAG C(T/C)T AGT CCC $3^{\prime}$ \\
\hline $\mathrm{JP}$ & $5^{\prime}$ TGT AAT GAT AAG CTT TGT TCC 3' \\
\hline
\end{tabular}

TCR, T-cell receptor. 
ductal and periacinar lymphocytic infiltrates, formation of lymphoid follicles, and periductal fibrosis of varying intensity. On the basis of these features, the chronic sialadenitis was diagnosed as chronic sclerosing sialadenitis. Seven cases were in Stage 2, 11 cases in Stage 3, and 4 cases in Stage 4. In none of the cases were microliths detected.

An immunohistochemical analysis of the lymphocyte subsets in the lymphocytic infiltrate revealed that CD3-positive T cells were clearly dominant over CD20-positive B cells. The majority of the periductal and periacinar lymphocytes were cytotoxic $\mathrm{T}$ cells characterized by CD8 expression (Fig. 1). However, T cells were also found in intraepithelial sites (Fig. 2A). The ratio of CD4 to CD8 T cells was 1 to 2 . The quantity of CD4- and CD8positive cells was slightly greater than that of CD3 cells (Fig. 1). Granzyme B, an antigen expressed by activated cytotoxic lymphocytes, was demonstrated in periductal and periacinar lymphocytes of all cases (Fig. 2B). B lymphocytes expressing CD20 and $\mathrm{Ki}$-B3 were restricted to lymphoid follicles (displaying germinal center formation) in 20 of 22 cases (Fig. 2C). Lymphoepithelial invasion by B lymphocytes was seen in 21 of 22 cases (Fig. 2D). The intraepithelial B lymphocytes were frequently KiB3-positive monocytoid B cells. In all cases, moderate numbers of randomly dispersed plasma cells were seen. Conspicuous clusters of plasma cells were not found. Ki-M1P staining revealed scattered macrophages and monocytic/cells evenly distributed over periductal, periacinar, and intraepithelial sites. Small foci of epithelioid cells and single Langhans' giant cells were found in small clusters in 11 of 22 cases (Fig. 2E), and monocytes with a plasmacytoid appearance, in 9 of 22 cases (Fig. 2F). An inversely proportional relationship was observed between the degree of fibrosis and the number of macrophages (Fig. 3).

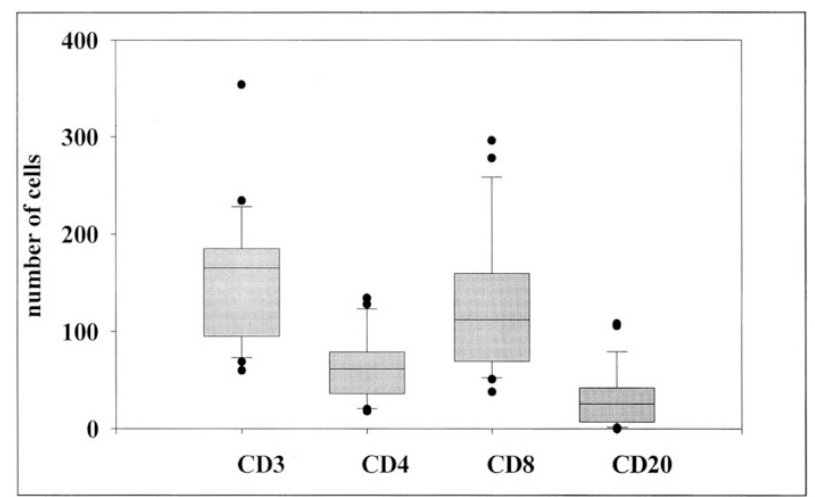

FIGURE 1. Analysis of the periductal and periacinar lymphocyte subpopulations in chronic sclerosing sialadenitis by quartiles and box plots.

\section{Molecular Genetics}

The analysis of TCR $\gamma$ rearrangements revealed a monoclonal pattern in 6 cases $(27.3 \%)$ and an oligoclonal pattern in 8 cases $(36.4 \%)$. The remaining 8 cases $(36.4 \%)$ showed polyclonal TCR rearrangements. PCR analysis of IGH gene rearrangements resulted in a polyclonal pattern in 17 cases $(77.3 \%)$, an oligoclonal pattern in 2 cases (9\%), and a monoclonal pattern in 3 cases (13.6\%; Figs. 4 and 5). There was no correlation between the molecular pattern and the stage of chronic sclerosing sialadenitis of the submandibular gland.

\section{DISCUSSION}

The diagnosis of chronic sclerosing sialadenitis in the submandibular glands rests on the presence of a lymphocytic and monocytic inflammation causing septal and periductal fibrosis and parenchymal loss. Histologically, chronic sclerosing sialadenitis seems to evolve through four stages, starting as a mainly periductal lymphocytic inflammation and ending as an inflammatory fibrosis that destroys the acinar structure of the gland. None of our cases was in an initial stage of chronic sclerosing sialadenitis. In Stages 2 and 3, there was already an intense infiltrate of periductal and intraepithelial cytotoxic $\mathrm{T}$ cells and an increase in intraepithelial macrophages. The total number of CD3-positive $\mathrm{T}$ cells was somewhat lower than that of CD4-positive and CD8-positive T cells together. Consequently, it could be assumed that isolated $\gamma \delta$-positive cells or cytotoxic NK cells were present. Particularly in Stage 2, we observed a periductal increase in B cells, which sometimes formed germinal centers. In addition, there were monocytoid B cells invading the duct epithelium. However, this did not result in typical lymphoepithelial lesions, as seen in Sjögren's syndrome. The largest number of macrophages was found in Stages 3 and 4. In addition to macrophages, occasional epithelioid cells, Langhans' giant cells, and plasmacytoid monocytes were present. With increasing sclerosis, the number of cytotoxic T cells and macrophages decreased.

So far, only one immunohistochemical study of chronic sclerosing sialadenitis is available. In an investigation of three cases, Ikeda et al. (10) demonstrated B lymphocytes (CD19, CD20) in lymphoid follicles. In the same paper, $\mathrm{T}$ cells (CD3) were found in the periphery of lymphoid follicles, and the number of T-helper cells (CD4) significantly exceeded that of cytotoxic T cells (CD8). Cytotoxic $\mathrm{T}$ cells were found in the parafollicular zone of germinal centers and in interfollicular areas. These findings resemble those in antigenstimulated lymph nodes and suggest a local immune response. Our data confirm those of Ikeda et 

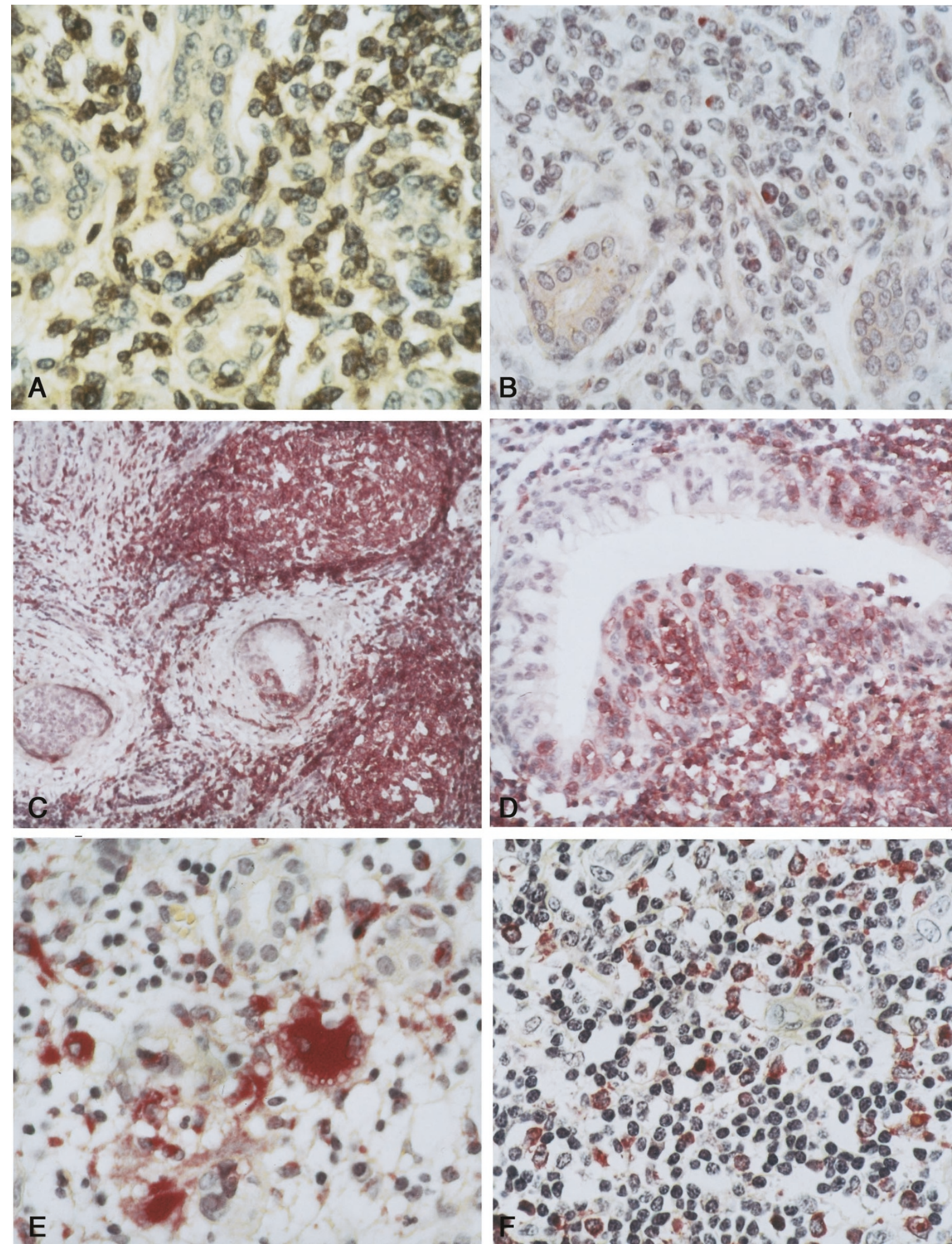

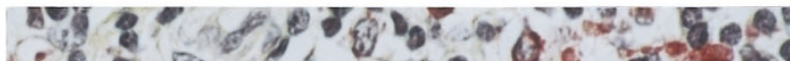

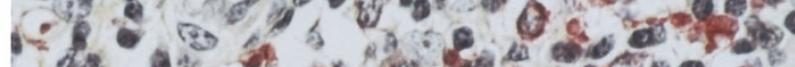

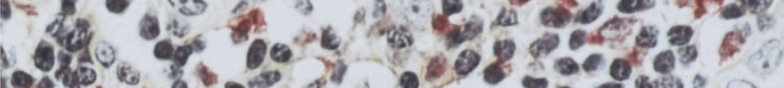

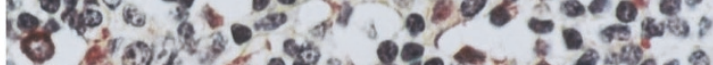

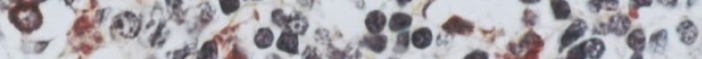

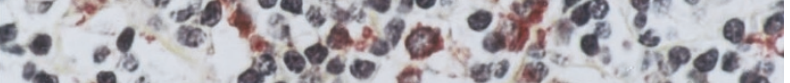

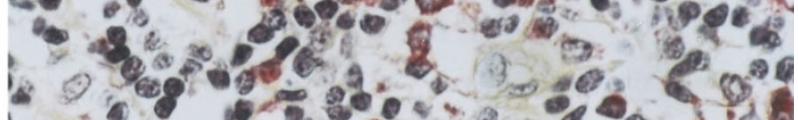
$1+2 \% 300 \%$

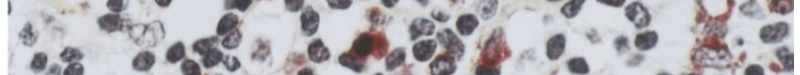

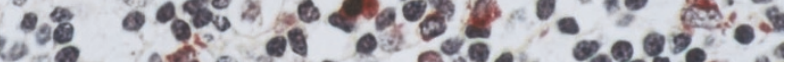

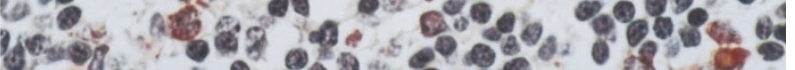

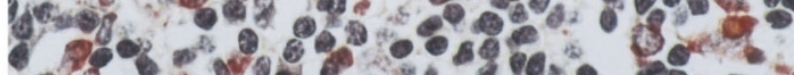

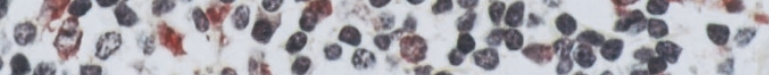

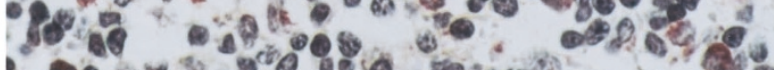
Folpos

FIGURE 2. Immunohistochemical analysis of chronic sclerosing sialadenitis of the submandibular gland. A, intraepithelial and periductal $\mathrm{T}$ cells in the early phase of Küttner tumor. CD3 staining, Strept-ABC method, $400 \times$. B, cytoplasmatic granzyme B staining of intra- and periepithelial cytotoxic T cells. APAAP method, $200 \times$. C, germinal center formation and intraepithelial B cells in the late phase of Küttner tumor. CD20 staining, APAAP method, 50×. D, intraepithelial B cells and salivary duct in Küttner tumor. CD20 staining, APAAP method, 100×. E, epithelioid cells and Langhans' giant cells in the late phase of Küttner tumor. Ki-M1P staining, APAAP method, 200×. F, plasmacytoid monocytes and macrophages in the middle phase of Küttner tumor. Ki-M1P staining, APAAP method, 200×. 


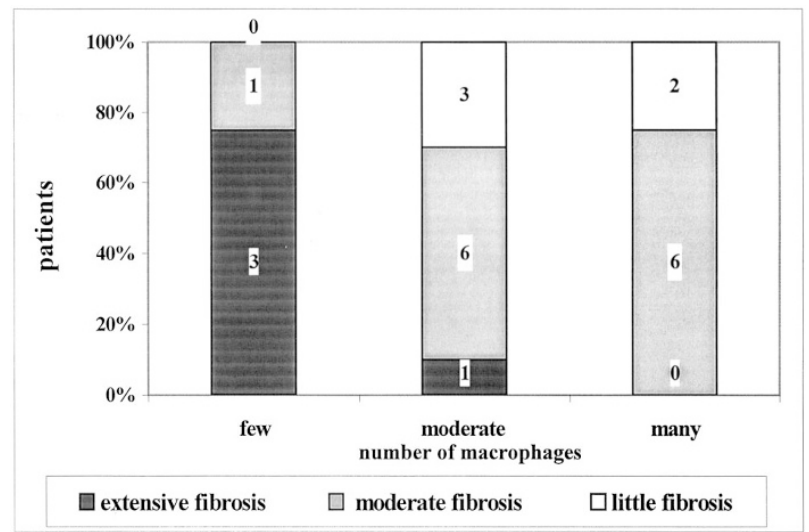

FIGURE 3. Amount of macrophages in relation to the grade of fibrosis.

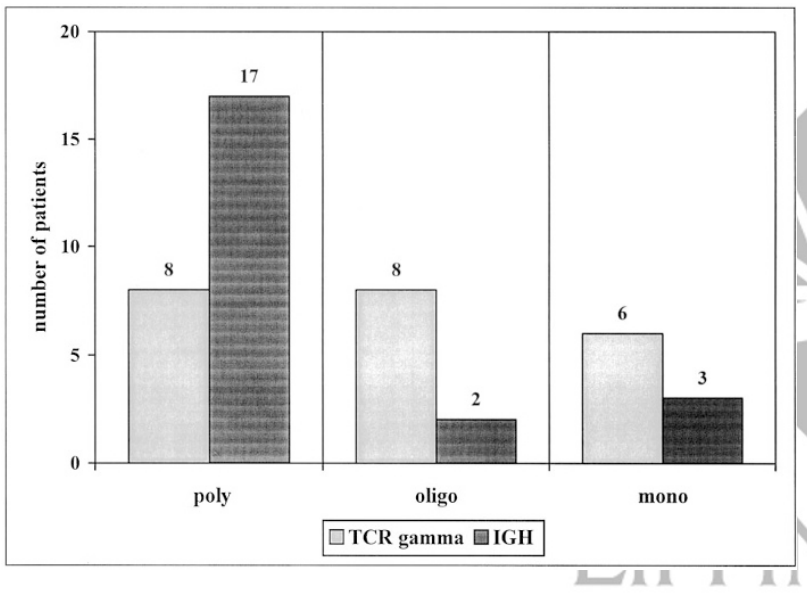

FIGURE 4. Results of the clonality analysis of the TCR $\gamma$ and IGH genes. poly $=$ polyclonal, oligo $=$ oligoclonal, $\overline{\text { mono }}=$ monoclonal .

al. (10) but additionally show that there are abundant cytotoxic $\mathrm{T}$ cells around ducts and between acini that are intimately related to epithelial cells.

The simultaneous appearance of intraepithelial cytotoxic $\mathrm{T}$ cells and invasion of the epithelium by B cells suggests a synchronous response of the B and $\mathrm{T}$ cell systems to a stimulus that is probably provided by the duct and acinar cells. The abundance of $\mathrm{T}$ cells, however, indicates that the T-cell system plays the predominant role in this process. It also seems that the invasion of the epithelium by cytotoxic $\mathrm{T}$ cells is independent of the immune reactions in and around the lymphoid follicles. The presence of cytotoxic $\mathrm{T}$ cells within damaged tissue is indicative of an autoimmune disease $(17,18)$ but has also been seen in viral diseases, such as CMV and Epstein-Barr virus infection. In the meantime, several animal models have provided new evidence of such autodestructive processes $(19,20)$.

Autoimmune diseases are specific immune reactions against the patient's own antigens. At the present time, it is not known what triggers such autoimmune reactions, although a predisposition
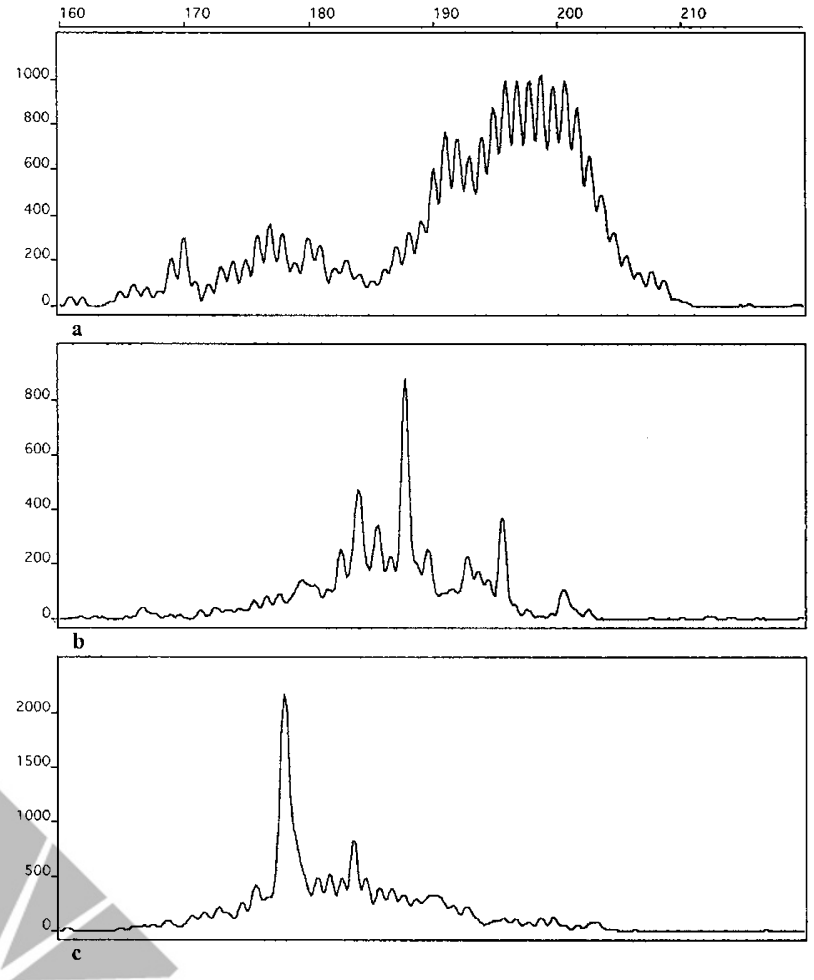

FIGURE 5. Automated high-resolution PCR fragment analysis. Electrophoretic profile of PCR products of the TCR $\gamma$ gene using DNA extracted from three different Küttner tumors. A, polyclonal pattern; B, oligoclonal pattern; C, monoclonal pattern.

of certain MHC genotypes has been found. Autoimmune reactions are extended processes and lead to severe tissue damage. During a spontaneous course of the disease, the process will come to an end once the autoantigens that evoked the immune response are eliminated by destruction of the cells that carry these antigens. This may explain the different stages in chronic sclerosing sialadenitis. Observations in experimental allergic encephalomyelitis in mice suggest that the lymphocytes in damaged tissue express only a limited number of variable T-cell receptor gene regions and react with a single or a few epitopes, as observed in organspecific autoimmune diseases (21-23). In autoimmune diseases such as multiple sclerosis or rheumatoid arthritis, a pronounced clonal expansion of $\gamma \delta \mathrm{T}$ lymphocytes has been observed $(17,18)$. In our series, a monoclonal/oligoclonal reaction of TCR $\gamma$ was observed in 14 of 22 (63.6\%) cases, and similar IGH rearrangement patterns were seen in 5 of 22 $(22.7 \%)$ cases. These findings are suggestive of an autoimmune process, because "normal" inflammatory reactions (as observed, e.g., in viral infections) usually show a polyclonal rearrangement pattern. The data fit well with our immunohistochemical data, including the increase in cytotoxic $\mathrm{T}$ cells, especially intraepithelial cytotoxic $\mathrm{T}$ cells. Compared with Sjögren's syndrome, the T-cell response is much more strongly affected in chronic scleros- 
ing sialadenitis than the B-cell reaction. The smaller part of cases presenting with polyclonal rearrangement pattern could be explained with real polyclonal inflammation or an overgrowth of smaller clones by a polyclonal background of reactive $\mathrm{T}$ cells.

We were not able to verify that these findings correlated with the occurrence of malignant lymphomas. In the Lymph Node Registry at Kiel University, we have not yet diagnosed a primary T-cell lymphoma of the salivary gland. The alterations described above did not result in MALT lymphomas in any of the cases in the Salivary Gland Registry of Hamburg University. By contrast, an increased incidence of MALT lymphomas has been observed in patients with Sjögren's syndrome $(24,25)$. MALT lymphomas do not develop in patients with chronic sclerosing sialadenitis, possibly because of the reduced stimulation of the B-cell response (compared with Sjögren's syndrome) and the absence of lymphoepithelial destruction caused by the lymphoepithelial lesions described above. Furthermore, an oligoclonal increase in cytotoxic $\mathrm{T}$ cells does not predispose a patient to the development of non-Hodgkin's T cell lymphomas. Primary extranodal non-Hodgkin's lymphomas of the head and neck originate from other non-thymus-dependent $\mathrm{T}$ cells or NK cells (26). It has also been observed that most of these tumors occur in Asian patients. Therefore, race and human leukocyte antigen patterns probably play a role in their development. In European patients, there seems to be no connection between autoimmune diseases of the salivary glands and the development of the mentioned non-Hodgkin's lymphomăs.

In summary, chronic sclerosing sialadenitis of the submandibular gland shows the features of an autoimmune process in which CD8-positive cytotoxic T cells and macrophages participate. An autoimmune-like reaction is suggested by the common occurrence of oligoclonal TCR $\gamma$ rearrangements and the destruction of glandular epithelium by activated cytotoxic T lymphocytes. The antigen that could cause the immune reaction in chronic sclerosing sialadenitis is not known.

Acknowledgments: The excellent technical assistance of Mrs. M. Hauberg, Mrs. D. Haupt (Immunohistochemical Labor), Mrs. C. Boie, and Dr. K. Heidorn (Gene and Isotope Labor) is gratefully acknowledged. We also thank Mrs. K. Dege for language editing.

\section{REFERENCES}

1. Küttner H. Über entzündliche tumoren der submaxillarspeicheldrüse. Bruns'Beitr Klin Chir 1896;15:815-28.

2. Seifert G. Tumour-like lesions of the salivary glands. The new WHO classification. Pathol Res Pract 1992;188:836-46.

3. Seifert G, Sobin LH. The World Health organization's histological classification of salivary gland tumors. A commentary on the second edition. Cancer 1992;70:379-85.
4. Rauch S. Speicheldrüsenmykosen und küttnersche krankheit. Pract Oto-Rhino-Laryngol 1959;21:333-48.

5. Lentrodt J. Beitrag zur kenntnis der küttnerschen tumoren. Dtsch Zahnärtzebl 1964;18:125-31.

6. Isacsson G, Ahlner B, Lundquist PG. Chronic sialadenitis of the submandibular gland. A retrospective study of 108 cases. Arch Otorhinolaryngol 1981;232:91-100.

7. Harrison JD, Epivatianos A, Bhatia SN. Role of microliths in the aetiology of chronic submandibular sialadenitis: a clinicopathological investigation of 154 cases. Histopathology 1997;31:237-51.

8. Chan JK. Kuttner tumor (chronic sclerosing sialadenitis) of the submandibular gland: an underrecognized entity. Adv Anat Pathol 1998;5:239-51.

9. Rasanen O, Jokinen K, Dammert K. Sclerosing inflammation of the submandibular salivary gland (Kuttner tumour). A progressive plasmacellular ductitis. Acta Otolaryngol 1972;74:297-301.

10. Ikeda M, Ikui A, Tanaka M, Omori H, Tomita H. Immunohistopathological investigation on unspecific chronic sclerosing sialadenitis of the submandibular gland (Kuttner tumor). Auris Nasus Larynx 1994;21:103-10.

11. Seifert G, Donath K. On, the pathogenesis of the Kuttner tumor of the submandibular gland-analysis of 349 cases with chronic sialadenitis of the submandibular. HNO 1977;25:81-92.

12. van KJ, von SC, Kluin PM, Lennert K. Splenic marginal zone lymphocytes and related cells in the lymph node: a morphologic and immunohistochemical study. Hum Pathol 1989;20:320-5.

13. van KJ, Lennert K. Proliferation of marginal zone cells mimicking malignant lymphoma. Pathol Res Pract 1990;186:397-9.

14. Radzun HJ, Hansmann ML, Heidebrecht HJ, BodewadtRadzun S, Wacker HH, Kreipe H, et al. Detection of a monocyte/macrophage differentiation antigen in routinely processed paraffin-embedded tissues by monoclonal antibody Ki-M1P. Lab Invest 1991;65:306-15.

15. Wan JH, Trainor KJ, Brisco MJ, Morley AA. Monoclonality in B. cell lymphoma detected in paraffin wax embedded sections using the polymerase chain reaction. J Clin Pathol 1990;43:888-90.

16. Trainor KJ, Brisco MJ, Wan JH, Neoh S, Grist S, Morley AA. Gene rearrangement in $\mathrm{B}$ - and T-lymphoproliferative disease detected by the polymerase chain reaction. Blood 1991;78:192-6.

17. Wucherpfennig KW, Newcombe J, Li H, Keddy C, Cuzner ML, Hafler DA. Gamma delta T-cell receptor repertoire in acute multiple sclerosis lesions. Proc Natl Acad Sci U S A 1992;89:4588-92.

18. Olive C, Gatenby PA, Serjeantson SW. Evidence for oligoclonality of $\mathrm{T}$ cell receptor delta chain transcripts expressed in rheumatoid arthritis patients. Eur J Immunol 1992;22:2587-93.

19. Ishimaru N, Yoneda T, Saegusa K, Yanagi K, Haneji N, Moriyama K, et al. Severe destructive autoimmune lesions with aging in murine Sjogren's syndrome through Fasmediated apoptosis. Am J Pathol 2000;156:1557-64.

20. Ishimaru N, Saegusa K, Yanagi K, Haneji N, Saito I, Hayashi Y. Estrogen deficiency accelerates autoimmune exocrinopathy in murine Sjogren's syndrome through fas-mediated apoptosis. Am J Pathol 1999;155:173-81.

21. Padula SJ, Sgroi DC, Lingenheld EG, Love JTJ, Chou CH, Clark RB. T cell receptor beta chain gene rearrangement shared by murine $\mathrm{T}$ cell lines derived from a site of autoimmune inflammation. J Clin Invest 1988;81:1810-8.

22. Acha-Orbea H, Mitchell DJ, Timmermann L, Wraith DC, Tausch GS, Waldor MK, et al. Limited heterogeneity of T cell receptors from lymphocytes mediating autoimmune encephalomyelitis allows specific immune intervention. Cell 1988;54:263-73.

23. Marguerie C, Lunardi C, So A. PCR-based analysis of the TCR repertoire in human autoimmune diseases. Immunol Today 1992;13:336-8.

24. Kassan SS, Thomas TL, Moutsopoulos HM, Hoover R, Kimberly RP, Budman DR, et al. Increased risk of lymphoma in sicca syndrome. Ann Intern Med 1978;89:888-92. 
25. Talal N, Sokoloff L, Barth WF. Extrasalivary lymphoid abnormalities in Sjogren's syndrome (reticulum cell sarcoma, "pseudolymphoma," macroglobulinemia). Am J Med 1967; 43:50-65.
26. Chiang AK, Chan AC, Srivastava G, Ho FC. Nasal T/natural killer (NK)-cell lymphomas are derived from Epstein-Barr virus-infected cytotoxic lymphocytes of both NK- and T-cell lineage. Int J Cancer 1997;73:332-8.

\section{Book Review}

\section{Laposata M: Laboratory Medicine: Clinical Pathol- ogy in the Practice of Medicine, 569 pp, Chi- cago: American Society for Clinical Pathology, 2002.}

Pathology departments of medical schools (in the USA at least) are innately occupied with didactic transitions and interdisciplinary connections. Their teaching of medical students falls chronologically between the basic and the clinical sciences. Their members often supervise the chemical and microbiological laboratories that are the service centers of hospitals. They generate cold facts but are expected to aid in complicated diagnoses. The modern trend is to explain themselves by embracing riders, for example by becoming a Department of Pathology and Laboratory Medicine. It would seem that "Laboratory Medicine" is the interface between "analyses and tests" on the one hand and "integrations and medical interventions" on the other. Michael Laposata tells us in his preface that there couldn't be anything more vital for practicing physicians, and yet in many schools it is limited to a few scattered lectures in the curriculum. The present book is offered to students as a "topic-by-topic presentation of laboratory medicine that parallels the treatment in the dominant second-year anatomic pathology texts, whether $R u$ bin \& Farber Pathology or Robbins' Pathologic Basis of Disease." The target audiences are "current medical students in the pathology curriculum and the former medical students who now make up the ranks of practicing physicians."

The opening chapter addresses basic concepts including the "normal range" for analytes. Practically speaking, this includes $95 \%$ of "healthy" individuals and by definition $5 \%$ fall outside this range without expressing disease. If 20 different tests are ordered on a healthy man or woman, the chances are high that one of those tests will yield an abnormal value. This is about the extent of statistics conveyed in this text, and discussions of other concepts likewise gravitate toward the simplistic. However, the choices of analogies, metaphors, and full-page illustrations make for easy and informative reading.

Diagrams abound in the methods section (Chapter 2, pages 16-91) and vary in complexity from simple "blood smear" to more complicated "lipoprotein analysis." There is an instructive, diagrammatic flow- chart showing the reader how to do a Gram Stain and another on how to streak an agar plate toward isolating colonies from single microbial cells. In the latter case, one has to consult the text to see that the transfer needle is flamed between sectors; and the artist's scribe lines in the successive fields are not quite right (it's the old conflict between content and clutter). Such minor criticisms are very few in number. Inevitably, if for no other reason than concern about the length and weight of the book, a few problems of topic selection and extent of coverage pop up. There is no discussion on how to measure glucose apart from one of many analytes on a dip-stick. Perhaps this is the ultimate modern case of black-box, samples-in, numbers-out technology. Supposedly only the dinosaurs know how to do it by hand. For more than a decade, medical graduates from my own university have never performed a Gram stain or a blood glucose! More's the pity.

Chapters 3 through 7 address various classes of disease, for example autoimmune disorders, infectious diseases, diseases of childhood and infancy. Chapters 8 through 22 are in concert with the anatomic pathology treatment promised earlier: blood vessels, the heart, red blood cells, and so on. These sections are rich in diagnostic tables and aids to interpretation.

Laboratory Medicine is well produced on good quality paper. Informative tables appear in the best places. For example, cap colors for blood tubes appears early (page 11) and there is good fidelity between that table and the colors in the subsequent illustrations. The quality of the figures (due to Dr. Z. Szczepiorkowski) is always high and is judged a feature of this book. The index is adequate. The position of page numbers (little boxes half way down in the left or right margin) is unusual but actually works, it turns out to be the easiest place to spot them in a book this size. In summary, Dr. Laposata speaks from experience and displays a great commitment to his subject. His book fills a gap in the field and should find wide usage.

\section{Wilfred Niels Arnold}

University of Kansas Medical Center

Kansas City, Kansas 